\title{
Industrial Policy: Domestic Challenges, Global Imperatives, and Pakistan's Choices
}

\author{
Shahid Javed Burki*
}

\begin{abstract}
Public policy is aimed at increasing the efficiency of the industrial sector in Pakistan. This paper looks at four issues. Firstly, it looks at the adjustments the new government needs to make to restore macroeconomic balance. Secondly, it discusses the global changes that have occurred in the industrial sector and how these could be incorporated into Pakistani policy making. Thirdly, I have briefly discussed the history of policies implemented in Pakistan. Lastly, I have discussed the importance of decentralized industrial policy making. This paper also conducts an empirical analysis of the impact of industrialization on poverty. It is concluded that industrial development in Pakistan has historically been heavily dependent on government intervention and there was poor growth in this sector as compared to other Asian economies. The paper also presents five proposals aimed at achieving higher growth in the industrial sector.
\end{abstract}

JEL Classification: D33, H32, L12, L13

Keywords: Pakistan, Public Policy, Industry, Competitiveness, Poverty

\section{Introduction}

In the past policymakers in Pakistan were inclined to keep two objectives in view while designing public policy aimed at industrializing the country. The first was to gain self-sufficiency in items of basic consumption; the second, was to exploit the country's perceived comparative advantage. In both cases the industrial policy overlapped considerably with trade policy; at times it was concern with some aspects of international trade that determined the content and orientation of the industrial policy. To take one example: The Indo-Pakistan trade war of 1949 forced Pakistan into adopting the first approach - to attempt for self sufficiency in basic manufactures. The model of planned growth adopted by the Government of President Ayub Khan led to

\footnotetext{
${ }^{*}$ Head, Policy Institute, Beaconhouse National University (BNU) and Former Minister of Finance, Government of Pakistan.
} 
the second approach - to develop industries using the country's comparative advantage. Neither of the two approaches created an efficient industrial sector.

Instead, as I will argue in this paper, Pakistan needs to adopt an approach based on three considerations: selecting the winners, both industries and enterprises, that could exploit niches for themselves in the rapidly changing global system of production; decentralizing industrial policymaking to the provinces so that each province can take advantage of its endowments; choosing the industries that can play a role in creating a large number of jobs for the country's rapidly increasing work force. With this as the approach the country will have not one but a number of industrial policies - at least four, one for each province of the country. In Punjab, to take one example, the policy will aim at expanding the food processing sector as well as small and medium industries focused on small engineering. In Sindh, to take another example, the industrial policy should take advantage of the large industries that are located in the province. The aim of policy should be to develop further the industrial base so that the existing industries and corporate entities working in the sector can acquire scale and expertise that would help them to compete with the tens of thousands of multinational corporations that are now operating in the global economy. The Indian industrial enterprises have been able to enter the global production system though mergers and acquisitions. Pakistan, however, has been left way behind.

This paper is presented in four parts. The first looks at the process of macroeconomic adjustment the new government needs to make in order to restore balance to the economy. I will argue that the adjustment needs to be done in a way that it does not compromise the country's growth prospects. The second section deals with how the global production, trading and financial systems have changed and what these changes mean for policymaking in Pakistan. The third section gives a brief historical view of industrial policymaking in Pakistan. This is done since I believe that the politics of economic decision-making is an under-analyzed subject. The fourth section picks up on the role the provinces can - and should - play in the making of industrial policy. If that were to be done, industrial development should proceed on very different tracks in the provinces. I will illustrate this by making use of the Punjab as a case study.

\section{The Need for Adjustment While Not Hurting Growth Prospects}

Recent economic developments pose many serious problems for today's policymakers. They have also created an opportunity for rethinking the priorities the state should adopt with respect to quickening the pace of 
development - Pakistan is now a laggard among the large economies of Asia. While promoting growth, policymakers must also decide the direction in which the economy should proceed. The policies that helped the economy to grow at 7 percent a year over the last half a dozen years did not do enough for the poor, widened interpersonal and inter-regional income gaps, and did not increase the integration of the economy with the global economic system. The model of growth pursued did not solve the deep rooted structural problems the economy has faced for decades while some more have been added to those that already existed.

Not for the first time in its turbulent economic history, policy makers in Pakistan are faced with some critical choices. The economy has lost its balance. The fiscal deficit is increasing at an unsustainable rate. It has already reached the level where financing it could lead to a number of unpleasant consequences. Resorting to borrowing from the central bank, as was done in the first half of 2008 would result in inflation. This is not the route the policymakers should take. It would exacerbate the inflationary pressures that are already present in the economy. On April 16, 2008 the new government revealed that the rate of increase in general inflation had doubled in the last one year, reaching 14.2 percent a year. The food inflation was at more than 20 percent a year. This rise in the level of prices was the result of both public policy and the rise in global commodity prices. The previous government had already borrowed heavily from the central bank while the price of oil and several agricultural commodities was increasing at unprecedented amounts.

The second way of financing the deficit would be to borrow from the market. This would raise interest rates and also crowd out private investors, inhibiting new investments in the economy. The third would be to reduce government's non-development expenditures. One way of reducing government expenditure and realigning its priorities would be to involve the provinces in the decision making process. What is required, therefore, is a balanced approach involving some central bank financing, some market borrowing, some privatization of the assets still owned by the government, and some reduction in the government's current expenditure. Whichever combination of policies is adopted, it should be done in a way that the economy's medium- and long-term growth objectives are not compromised. Adjustment should be done within the context of a mediumterm development framework ${ }^{1}$. Unfortunately, such a framework does not

\footnotetext{
${ }^{1}$ A comprehensive program for adjustment and growth was prepared by the Institute of Public Policy in its first annual report, Lahore, May 2008. See, the Institute of Public Policy (2008).
} 
exist. The Planning Commission's Vision 2030 spells out some long-term strategies but it did not guide policymaking by the previous regime ${ }^{2}$. The framework within which adjustments should be undertaken should have built-in trade, industrial and agricultural development policies. These policies should be developed with full recognition given to some of the important changes taking place in the structure of the global economy. The main purpose of this short paper is to present some ideas on industrial policy, although there is a considerable amount of overlap in the policy content of industrial and trade policies.

In this broad overview of the opportunities available to Pakistan in the industrial sector, we will focus on a number of considerations that should inform the policymakers as they seek to industrialize the country. One, they should be mindful of the history of industrial development in the country, a subject that we discuss in the section that follows. Two, the changes that have occurred in the global economic system - in both the system of industrial production as well the system of international trade should also be kept in mind as the policymakers begin to address this subject once again. Three, much of the industrial policy should be the responsibility of the provinces. This will lead to the state placing a different emphasis in different regions of the country. Four, this approach to policymaking should result in considerable emphasis on the development of small and medium enterprises. The development of this part of the industrial economy has not received as much state attention as it deserves.

\section{Global Changes: How the International Production and Trading Systems Have Changed and What These Changes Mean for Pakistan}

In the design of an industrial policy appropriate for the country at this time, Pakistan must factor in the changes that are taking place in the global economic system. Three of these are important. The global production system is changing rapidly as multinational corporations are able to use the rapid development in information and communication technologies to disperse their activities. The firms located in the industrial world are either outsourcing a great deal of what they used to do themselves or are taking their operations to the places that offer better prices for their inputs. This dispersal of activity has led to the second important change in the structure of the global economy. Now parts and components have become the largest component of international trade.

\footnotetext{
${ }^{2}$ Government of Pakistan (2007).
} 
That the changes in the global system of production and trade would suggest an industrial policy aimed at the development of small and medium industries with the ability to exploit external markets is reinforced by the fact that Pakistan today confronts a serious problem of poverty. What is the incidence of poverty is a hotly debated subject in the country. The previous government's claim that the incidence had declined by 10 percentage points is contested by a number of independent analysts, most notably Akmal Hussain and the Karachi-based Social Policy and Development Centre. Hussain ${ }^{3}$ claims that during 1998-99 and 2004-05, there was no significant reduction in the level of poverty. The SPDC found that the decline in poverty in 2004-07 was of the order of 3 to 3.5 percentage points rather than the much larger figure suggested by the previous government. The reason for recalling this debate is not to settle it one way or the other ${ }^{4}$. The purpose is to underscore the important point that the laissez faire approach to economic development that guided Islamabad did not do much to the incidence of poverty and to narrow the widening inter-personal and inter-regional disparities. The policymakers during this period placed their faith in what was once called the "trickle down" approach to economic development.

If alleviating poverty is to be one of the main objectives of public policy, then it is clear that a new approach to industrialization should be one of its important components. Generation of employment should, therefore, be built into the industrial policy. This is one additional reason why Pakistan needs to focus public policy on the development of small and medium sized industries.

Why can't investment choices be left to the private sector as advocated by the exponents of The Washington Consensus? This approach, articulated by the development finance institutions located in Washington, sought to reduce the role of the state in the management of the economy and promoting that of private enterprise. It also advocated more openness of the economy to the outside world by removing constraints on trade and the movement of capital. It may work in the economies where the private sector has developed without much handholding by the government. That is not the case in Pakistan. As noted below in the discussion of the history of industrial policy in the country, it was the government that was behind the development of private enterprise. Given that leaving further industrial development to private entrepreneurs is not likely to serve national interests, the state will need to play an important role. But the nature and

\footnotetext{
${ }^{3}$ Hussain (2008).

${ }^{4}$ Social Policy Development Centre (2007).
} 
scope of this should be different from those performed in the first sixty years of independence.

History of Industrial Policy-Making in Pakistan; Why Those Who Seek To Influence Policy-Making and Those Responsible For It Should Understand the Considerations That Motivate Various Stake Holders

The making of industrial policy in Pakistan has a chequered history. Industrial policies were made as either part of the medium-term development plans or in response to some crisis or other the country was faced with. Five industrial policies or distinct approaches have left a lasting impression on the structure of industry in the country. The first was made in 1948, soon after Pakistan gained independence, and was developed further as a consequence of the Indian decision in 1949 to place a trade embargo on Pakistan. The second was embedded in the Second (1960-65) and Third (1965-70) Five-year Development Plans adopted by the government headed by President Ayub Khan, the county's first military ruler, the third was adopted by the administration of President (1ater Prime Minister) Zulfikar Ali Bhutto, the fourth was formulated by the several democratic governments that held office in the eleven year interregnum, 1988-1999, between two long rules by the military, and the fifth was adopted by the government of President Pervez Musharraf, the fourth military ruler. It would be in order to briefly discuss the approaches adopted in these five separate policies to prepare the ground for the discussion of what I believe should be the content of a new policy.

The first generation of Pakistani leaders was extremely concerned with the Indian attitude towards the country they had created. There was an impression that the Indian leadership would attempt to smother Pakistan by using economic means. This feeling was reinforced by some of the early decisions taken by New Delhi regarding the release of funds that were due to Pakistan as a result of the Partition Agreement. The Indian government blocked the transfer of funds that fell in the category of what was called the "Sterling Balances". When, in 1949, Pakistan chose not to follow other countries of what was then called the Sterling Area (now the Commonwealth) in devaluing its currency with respect to the American dollar, India retaliated by launching a trade war against its neighbor. Pakistan at that point was dependent on India for the supply of basic goods of consumption; a significant proportion of its imports came from India and a significant proportion of its exports went to that country. The Indian reaction to the Pakistani decision with respect to the value of its currency

${ }^{5}$ See Wolpert (2001), Chapter 24. 
caused enormous deprivation. The government responded by adopting a series of policies that were to have a lasting impact on the development of the country's industrial base. Karachi, at that time the country's capital, encouraged private leadership in the process of industrialization, provided incentives to private entrepreneurs to invest in the production of consumption goods, and gave the fledging private sector protection from external competition. All this resulted in the rapid growth of the industrial sector and rapid increase in the rate of increase in industrial output. It is interesting to note that while India had chosen to industrialize by encouraging the establishment of heavy industry in the industrial sector, Pakistan went in the opposite direction. It encouraged the development of private enterprise and growth of consumer industries.

The government of Ayub Khan continued with this approach but with two differences. It used the industrial licensing policy to bring about a wider dispersal of industrial ownership. And, it used development finance companies such as the Pakistan Industrial and Commercial Investment Corporation (the PICIC) and the Industrial Development Bank of Pakistan (the IDBP) to influence the scope of industrialization. PICIC and IDBP received generous financial support from the World Bank. Development thinking at that time was in favor of using publicly owned development finance corporations to quicken the pace of industrialization. An important consequence of this policy was to encourage the establishment of small units in the areas other than Karachi, which by then had emerged as the industrial center of the country. Textile spinning and weaving sectors were most affected by this policy. Dozens of spinning mills with no more than 12,500 spindles were set up. This was significantly below the optimal scale even at that time. The approach adopted by the Ayub government was to introduce considerable inefficiency in the sector, a development that has continued to keep the textile industry relatively backward to this day.

The third approach towards industrialization occurred during the first few months of the tenure of the administration headed by Zulfikar Ali Bhutto. ${ }^{6}$ His decision to nationalize large scale industries suddenly increased the presence of the public sector in industry and finance. By this action he sought to take Pakistan on the route and in the direction on which India under Jawaharlal Nehru had embarked after gaining independence. The decision to set up a number of public sector corporations to undertake new investments in the industrial sector and to provide financial support to them through a new development finance corporation, further strengthened the role of the state in the industrial sector. The result was the introduction of

\footnotetext{
${ }^{6}$ Burki (1980).
} 
several distortions into the management of the economy and widespread corruption that has continued to bedevil the country to this day.

The democratic administrations that held office in the 1990s took some initiatives to bring back the private sector as the leader in economic development by privatizing some of the state's economic assets, in particular large banks and large industries. But privatization did not lead to a bursting of industrial activity on the parts of the large owners of assets in the sector. There was no attempt at product innovation, not much attention given to technological improvement, and very little effort made at market penetration. The old industrial families with their assets restored to them went about doing business in the old way. While the government was stepping back from direct involvement in industrial management, large private sector industrialists were not prepared to let go the hand of the government. They were not prepared to step back but wished to stay close to the government.

From our perspective, the most important policy initiative of this period was the establishment of the Small and Medium Enterprise Development Authority, the SMEDA. This was set up in October 1998, as a federal corporation with four regional offices, one in each province of the country. The corporation's mandate was to facilitate the development of small and medium-sized enterprises by helping them to improve their line of products, introducing the entrepreneurs to new technologies, introducing them also to new ways of doing business and new management practices, helping them to do cost benefit analysis of the investments they were contemplating to make, and making them aware of the opportunities available in both internal and external markets.

However, it was only under President Pervez Musharraf that the private sector acquired a very prominent role. This was the fifth approach to industrial policymaking in the country's history. Under it, the pace of privatization quickened as did deregulation and the opening of the economy to the outside world. Some significant adjustments were made in the tariff regime that provided incentives for the development of such large scale industries as automobiles and consumer electronics. The government also gave considerable room to the financial sector to participate in the process of industrialization by making choices made on the basis of market considerations.

The amount of room for maneuver allowed to the private sector did not develop enough confidence among the entrepreneurial class to stand on its own feet and deal with the changes occurring in the globe economic system without government intervention. The failure of the textile industry 
to make use of the opportunities created by the end of the Multi-fiber Arrangement (MFA) on January 1, 2005 is the most telling example of the lasting impact on entrepreneurial behavior of the policies and approaches towards industrialization adopted in the past several decades.

While allowing considerable space to the private sector within the industrial domain, the Musharraf government should have also developed the regulatory system to provide protection to consumers, encouraging competition in the private sector, and improving corporate efficiency. Several regulatory bodies were set up in the sectors of finance, industry and public utilities but they were not allowed the autonomy without which they could not effectively operate. One way of ensuring the independence of the regulatory agencies from control of or influence by the executive branch of the government is to have the legislature approve the appointments of the chief executive. Although the Musharraf government created a number of regulatory bodies it appointed heads of the agencies who were close to the government. Consequently, most agencies did not achieve the desired amount of autonomy.

This brief history of Pakistan's industrial development shows the changes that occurred in the way those who held the reins of power looked at the sector. The frequent changes in industrial policy noted above have kept the industrial sector relatively backward compared to the developments in other large Asian economies. How should the government approach the sector now that political power is in the process of passing to the elected representatives of the people?

\section{The Need for a Larger Provincial Role in the Making of Industrial Policy and if That Were to Happen What is the Most Appropriate Course the Government Should Adopt?}

For the reasons already discussed, the state has a diminished role to play in industrial development compared to its very active involvement in earlier times. The withdrawal of the state does not mean completely surrendering the area to the private sector. If that were to be done - and to some extent this was done during the just concluded Musharraf era - the pace of industrial progress would be slow and its direction not totally appropriate for the country. I believe that the state needs to be invited back to play a more significant role in industrialization than was advocated by those who believed in The Washington Consensus.

Given Pakistan's history and the structure of its politics it would be right to divide the role of the state into five fairly distinct parts. These are 
picking the winners towards which the private sector should be guided but not forced. The ultimate decision to invest should be entirely the responsibility of the private entrepreneur. Second, once the decision has been taken to invest, a number of "facilitation" activities should be carried out, preferably by government agencies. The type of facilitation functions that state agencies can meaningfully perform were discussed above in the context of the mandate currently available to SMEDA. Third, better cooperation between the industrial and financial sectors should be encouraged so as to meet the financial needs of industry. Fourth, there must be attention paid to research and development, without which the industries located in the country will not be able to increase the level of productivity required for competing in the global market place. Fifth, a regulatory system needs to be in place aimed at preventing the development of monopolies in various sectors of the economy in which private entrepreneurs are actively involved. Once we disaggregate government's functions, we need to identify what is the most appropriate place for their location. In the past, the central government has tended to concentrate these activities in its hands, leaving out the provinces. This tendency to centralize economic policymaking needs to change in favor of greater involvement of the provinces. Were that to happen, the policies each province will adopt will better suit their circumstances. I will develop this point with reference to Punjab.

I believe that the province of Punjab, recognizing its endowment and recognizing also its geographic location should pay particular attention to the development of small and medium enterprises. It has a well developed skill base for developing a number of industries for which appropriate inputs are available. These include ag-processing, small-scale engineering, leather products, and the IT industry. This is an illustrative list of possible "winners" needing the support of the government. They could become the focus of the state's attention.

Having chosen the winners, the province should redefine the role of the SMEDA. The corporation should be divided into six separate entities, four for each of the four provinces and one each for the Federally Administered Tribal Areas (FATA) and Azad Jammu and Kashmir. These corporations should work to promote the development of the industrial sector in ways that conform to the comparative advantage of each geographic entity. By focusing on the development of an existing corporation, the Pakistani state will not need to create a new government enterprise.

As already discussed, the SMEDA is concentrating its attention on what I called "facilitation" - helping the selected enterprises and entrepreneurs to establish new production facilities or improve those they are 
already operating. In addition, the corporation should stretch its mandate at both ends of the spectrum it is currently engaged in. It should do more analytical work aimed at identifying the "winners" and in helping its clients access sources of finance. Winners should be identified by carefully studying the opportunities available in both domestic and external markets for products. This examination should lead to the identification of niches into which the country could move. For the Punjab, these niches are likely to be in the areas already indicated.

Having picked the winners, the corporation should continue with its facilitation work but with greater attention given to developing appropriate technologies aimed at improving the productivity of the sectors chosen for attention. For that to be done effectively, the SMEDA will need to build the capacity to do R\&D work. Ideally this should be done in association with the private sector with the private entrepreneurs required to pay for the help they are receiving.

Another new area for the SMEDA would be to get engaged in facilitating the access to sources of finance by the selected winners. It would be important to acquaint the people and enterprises being helped with new instruments of finance that have been developed in recent years. These include private equity and venture capital which provide equity rather than loans in return for claiming a significant share in future profits once the selected enterprises become successful.

I will conclude by summing up the argument presented in this short paper. I have argued for the adoption of an industrial policy to provide Pakistan with an industrial base (so far not developed) that would exploit its many advantages. The five approaches towards industrial policy adopted for the last six decades lacked a long-term vision; they were mostly responses to the problems the policymakers thought they faced when they held the reins of power. In designing an industrial policy it would be much more efficient to shift the locus of policymaking to the provinces rather than retain it in the center. In applying this approach to the province of the Punjab, I have argued that the list of "winners" the government should work on should be focused on the development of small and medium enterprises. In developing this approach the government needs to create a new entity but work on the evolution of the one that has done some interesting and useful work in the last decade. The Small and Medium Enterprise Development Authority has been effective in developing some new areas but it needs to expand its activities to include analytical work aimed at selecting the winners as well as helping the winners' access new sources of finance. 


\section{References}

Burki, Shahid Javed, 1980, Pakistan under Bhutto, 1971-77, London, Macmillan.

Government of Pakistan, 2007, Vision 2030, Islamabad, the Planning Commission, Islamabad.

Hussain, Akma1, 2008, "Fallacy of Poverty Reduction", Dawn, February 20.

Institute of Public Policy, 2008, State of the Economy: Challenges and Opportunities, Lahore.

Social Policy Development Centre, 2007, Annual Report, 2007, Karachi.

Wolpert, Stanley, 2001, Gandhi's Passion: The Life Legacy of Mahatma Gandhi, New York, Oxford University Press. 